\title{
Development of numerical analysis and methane sensing application of highly sensitive quantum crystals based on tin dioxide prepared by hydrothermal
}

\author{
N. M. Shaalan ${ }^{1,2}$ (D) D. Hamad ${ }^{2}$ - Adil Alshoaibi ${ }^{1}$ - A. Y. Abdel-Latief ${ }^{2}$ - M. A. Abdel-Rahim ${ }^{2}$
}

Received: 22 February 2019 / Accepted: 13 May 2019 / Published online: 20 May 2019

(c) The Author(s) 2019

\begin{abstract}
The quantum size of materials is an effective property for specific physical applications. The theoretical approach helps in understanding the physical properties of these materials. $\mathrm{SnO}_{2}$ quantum crystals of $\sim 1.8-6.0 \mathrm{~nm}$ are prepared by a hydrothermal method. The size of crystals is smaller than the Debye length reported for $\mathrm{SnO}_{2}$ at $250{ }^{\circ} \mathrm{C}$. The emission spectra of the radiative recombination between conduction and valence bands show a blue shift, which confirms the electron confinement. The prepared materials are used for fabricating gas sensor tested for $\mathrm{CH}_{4}$ gas. The gas detecting measurements exhibited high sensitive quantum crystals, QCs, toward $\mathrm{CH}_{4}$. For the first time, a theoretical approach is formulated for the response of $\mathrm{SnO}_{2}$ toward $\mathrm{CH}_{4}$ to understand the sensing mechanism of the quantum crystals. The correlation between the theoretical and experimental results clarified the reason of the high response observed for the quantum crystals toward $\mathrm{CH}_{4}$. To conduct a high response, the crystal size should be comparable or less than the Debye length, which means that the crystal is fully depleted or in volume-depleted in the air. Thus, the high response obtained here is explained in terms of the proposed theoritical approach.
\end{abstract}

\section{Introduction}

Controlling the growth of the quantum crystals is essential for different applications. Also, the theoretical study of their quantum size is effective for understanding the performance of materials and their operation mechanism, as well. Improvement of the binary oxide nanomaterials to reach a

N. M. Shaalan

nshaalan@aun.edu.eg; nmohammed@kfu.edu.sa

Adil Alshoaibi

adshoaibi@kfu.edu.sa

D. Hamad

noniatypes@yahoo.com

A. Y. Abdel-Latief atta552001@yahoo.com

M. A. Abdel-Rahim

maabdelrahim@yahoo.com

1 Physics Department, Faculty of Science, King Faisal University, Al-Hassa, P.O. Box 400, Hofuf 31982, Saudi Arabia

2 Physics Department, Faculty of Science, Assiut University, Assiut 71516, Egypt high sensitivity and precise limitation can be achieved by controlling their growth and the thermal stability of these nanomaterials. Up to date, $\mathrm{SnO}_{2}$ has the attention of the researchers for gas sensing applications [1-4]. In some studies, the sensitivity realized toward the gas by using multielement composites can be achieved if the material size is well controlled. The sensors fabricated by $\mathrm{SnO}_{2}$ nanomaterials are promising sensors toward methane gas.

The methane gas is the main reason for the global warming and can replace oxygen and causes suffocation and explosion [5]. For the public health and environmental safety, on-site detection of methane is important. For detecting methane there are several expensive and bulky techniques are employed [6]. They are multifaceted in the operating procedures and not convenient for on-site use. Several research papers studied the oxide materials for methane detection [1-4, 7-18], but most of these materials show a low sensitivity toward methane at high operating temperatures. To our best knowledge, there is no theoretical approach proved the sensing mechanism of methane by oxide materials.

As it is known, the resistivity of an n-type oxide decreases upon exposure to a reducing gas, such as $\mathrm{CH}_{4}$, due to the reduction of the depletion layer. Thus, the large depletion 
layer of n-type materials is very important parameter for the sensing material. In other words, the fully depleted particle in the air is preferred to achieve a high sensitivity. The fully depletion is realized if the crystal size is less than twice the depth of the depletion layer which mainly depends on the adsorbed oxygen and intrinsic electrons in the bulk (defined by Debye length). The depletion layer of a thin film and sintered powders of $\mathrm{SnO}_{2}$ is about $3.0 \mathrm{~nm}$ at $250{ }^{\circ} \mathrm{C}$ as achieved by References [19, 20]. Thus, if the size of $\mathrm{SnO}_{2}$ becomes less than or comparable to $\sim 6.0 \mathrm{~nm}$, dramatically change in gas sensing performances toward the reducing gases may be observed.

In the current study, we attempt to synthesize thermally stable quantum crystals of $\mathrm{SnO}_{2}$ with size less than $6.0 \mathrm{~nm}$ to achieve the above mention goal. The synthesis is carried out by a hydrothermal method-modified with cetyltrimethylammonium (CTAB), which acts as a template for $\mathrm{SnO}_{2}$ during the growth. The crystal structure and thermal stability are studied by XRD and DTA. The confirmation of the confinement effect is optically investigated. $\mathrm{CH}_{4}$ sensing is systematically studied at various operating temperatures. A theoretical approach based on the reaction of adsorbed oxygen on the surface and the reaction of methane gas with the oxygen species is proposed to explain the obtained experimental results.

\section{Experimental details}

For the preparation of $\mathrm{SnO}_{2}$, hydrate tin chloride $\left(\mathrm{SnCl}_{4} \cdot 5 \mathrm{H}_{2} \mathrm{O}\right)$ was dissolved in distilled water, and then $\mathrm{NaOH}$ water-dissolved was added drop-wise to the tin solution. An amount of $1.0 \mathrm{~g}$ of CTAB was added into the mixture. The mixture was transferred to a Teflon-lined stainlesssteel autoclave. The autoclave was maintained at different temperatures of $100,120,140,160$, and $180{ }^{\circ} \mathrm{C}$ for $10 \mathrm{~h}$. Afterward, the product was centrifugated for obtaining the powder, which was washed with distilled water and ethanol and then dried at $60{ }^{\circ} \mathrm{C} / 1 \mathrm{~h}$.

The crystalline phase was examined by $\mathrm{X}$-ray diffractometer (model; Philips PW 1700, $\mathrm{Cu}-\mathrm{K} \alpha$ ) in range $15^{\circ}$ to $90^{\circ}$ with a speed of $0.06^{\circ} \mathrm{s}$. Scanning electron microscope (SEM) and high-resolution transmission electron microscope (HRTEM) (JEOL-JEM-2100 F) are used for the morphology and crystallinity confirmation. Fluorescence (FL) spectra were recorded in range 300 to $480 \mathrm{~nm}$ at room temperature by using Spectrofluorometer (Jasco, FP-6300 WRE) with an excitation wavelength of $290 \mathrm{~nm}$. The fine powder was used to study the thermal behavior using thermal analysis techniques TGA and DTA [SHIMADZU DTA$60 \mathrm{H}]$ simultaneous apparatus in the air atmosphere under non-isothermal condition. A constant weight of $5.0 \mathrm{mg}$ was used to drop off the effect of sample weight on the peak shape and temperature. Non-isothermal DTA thermo-grams were obtained at selected heating rates of $5-25 \mathrm{~K} / \mathrm{min}$ in the temperature range of 30 up to $800{ }^{\circ} \mathrm{C}$.

The tested gas sensor was fabricated by coating a layer of the fine powder on two gold electrodes deposited by DC sputtering. The fabricated sensor was thermally annealed at $400{ }^{\circ} \mathrm{C}$ for $30 \mathrm{~min}$ in the ambient air before inserting it into the testing chamber. The operating temperature was varied from the room temperature up to $400{ }^{\circ} \mathrm{C}$. Dry synthetic air mixed with various $\mathrm{CH}_{4}$ concentrations flows with $200 \mathrm{ml} /$ min rate to the testing chamber, which was connected to Horiba mass flow controllers (SEC-N112 MGM) for flow rate control, and computerized data acquisition (LXI Agilent 34972 A) for electrical measurements.

\section{Results and discussions}

\subsection{Quantum confinement and thermal stability}

$\mathrm{XRD}$ pattern of $\mathrm{SnO}_{2}$ rutile tetragonal structure is shown in Fig. 1. The broadening of the diffraction peaks is an indicator for the growth of the fine crystals. The crystallinity of $\mathrm{SnO}_{2}$ was enhanced by raising the hydrothermal temperature from 100 up to $180{ }^{\circ} \mathrm{C}$. For the samples prepared at 160 and $180{ }^{\circ} \mathrm{C}$, new diffraction peaks with less broadening are observed, showing more crystal orientations and higher crystallinity compared to the others. The powder of $\mathrm{SnO}_{2}$ was annealed at $400{ }^{\circ} \mathrm{C}$ for $2 \mathrm{~h}$. After annealing, the increase in crystallite size is insignificant, which confirms the thermal stability of the as-prepared product.

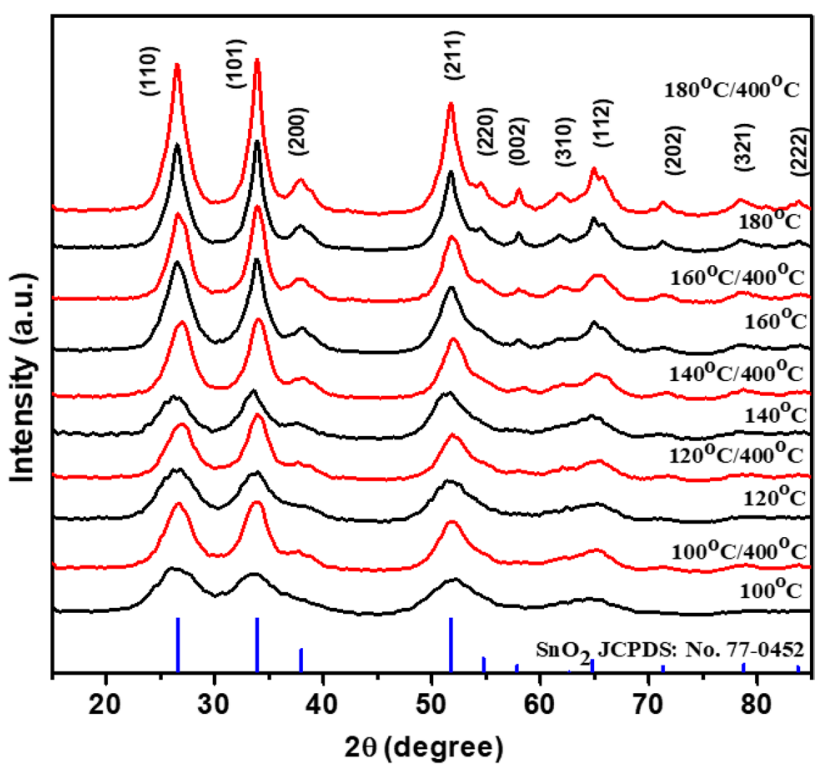

Fig. 1 XRD patterns of $\mathrm{SnO}_{2}$ quantum crystals before and after the annealing at $400{ }^{\circ} \mathrm{C}$ for $2 \mathrm{~h}$ 
The morphology of annealed $\mathrm{SnO}_{2}$ is shown in Fig. 2. Directional growth of grass-like structure based on quantum crystals, QCs, is observed after annealing for the samples prepared in $100-140{ }^{\circ} \mathrm{C}$. The growth of grass-like structure has the same crystallite size as indicated in HRTEM shown in Fig. 3. The crystal size was distributed in a range of $1.75-4.25 \mathrm{~nm}$, and $2.5-7.5 \mathrm{~nm}$ corresponding to an average size of $\sim 2.5$ and $5.0 \mathrm{~nm}$ for the preparation temperatures of 120 and $180^{\circ} \mathrm{C}$, respectively. The average size insignificant increased from 2.5 up to $3.6 \mathrm{~nm}$ and from 5.0 up to $5.8 \mathrm{~nm}$ after the annealing, as shown in Fig. 4.

The optical properties are used for confirming the confinement property of the fine materials. Thus, FL spectra were reported here in the wavelength range of $310-350 \mathrm{~nm}$ with an excitation wavelength of $\left(\lambda_{\mathrm{ex}}=290 \mathrm{~nm}\right)$. The normalized emission spectra of as-prepared and annealed $\mathrm{SnO}_{2}$ are shown in Fig. 5a and b. The FL spectra exhibited a blue shift with reducing the $\mathrm{SnO}_{2}$ size. The emission peaks can be attributed to the band edge emission that was caused due to the radiative recombination. As well known, if the size of nanocrystals is comparable or smaller than the quantum size, a stronger confinement exists, and the carriers become confined in this size [21].
The thermal behavior of $\mathrm{SnO}_{2}$ was simultaneously studied at different heating rates of $5 \mathrm{~K} / \mathrm{min}$ up to $25 \mathrm{~K} / \mathrm{min}$. A typical example of a combined plot of TGA/DTA for the $\mathrm{SnO}_{2}$ prepared at $120{ }^{\circ} \mathrm{C}$ at a heating rate of $15 \mathrm{~K} / \mathrm{min}$ is shown in Fig. 6a. The first region (I) which extends from 30 to $150{ }^{\circ} \mathrm{C}$ with a weight loss about $7 \%$ corresponds to an endothermic peak in DTA thermo-gram is due to the elimination of the physically adsorbed water on the surface of $\mathrm{SnO}_{2}$. The second region (II) which extends from 200 to $400{ }^{\circ} \mathrm{C}$ with a weight loss of $5 \%$, corresponding to an exothermic peak in DTA thermo-gram may be due to the elimination of a little amount of the chemically bonded water in $\mathrm{SnO}_{2}$ molecules. The third region (III) which extends after $400{ }^{\circ} \mathrm{C}$ with no weight loss reveals the thermal stability of $\mathrm{SnO}_{2}$ in this temperature range. A typical example of the TGA/DTA thermo-grams shown in Fig. 6b for $\mathrm{SnO}_{2}$ prepared at $120^{\circ} \mathrm{C}$ after annealing at $400{ }^{\circ} \mathrm{C} / 2 \mathrm{~h}$ reveals the absence of the exothermic peak. It means that the grown $\mathrm{SnO}_{2}$ crystals are thermally stable. On the other hand, the XRD patterns for the annealed samples prepared at 100,120 , and $140{ }^{\circ} \mathrm{C}$ reveal the decrease of peak broadening and an increase of the peak intensity compared to
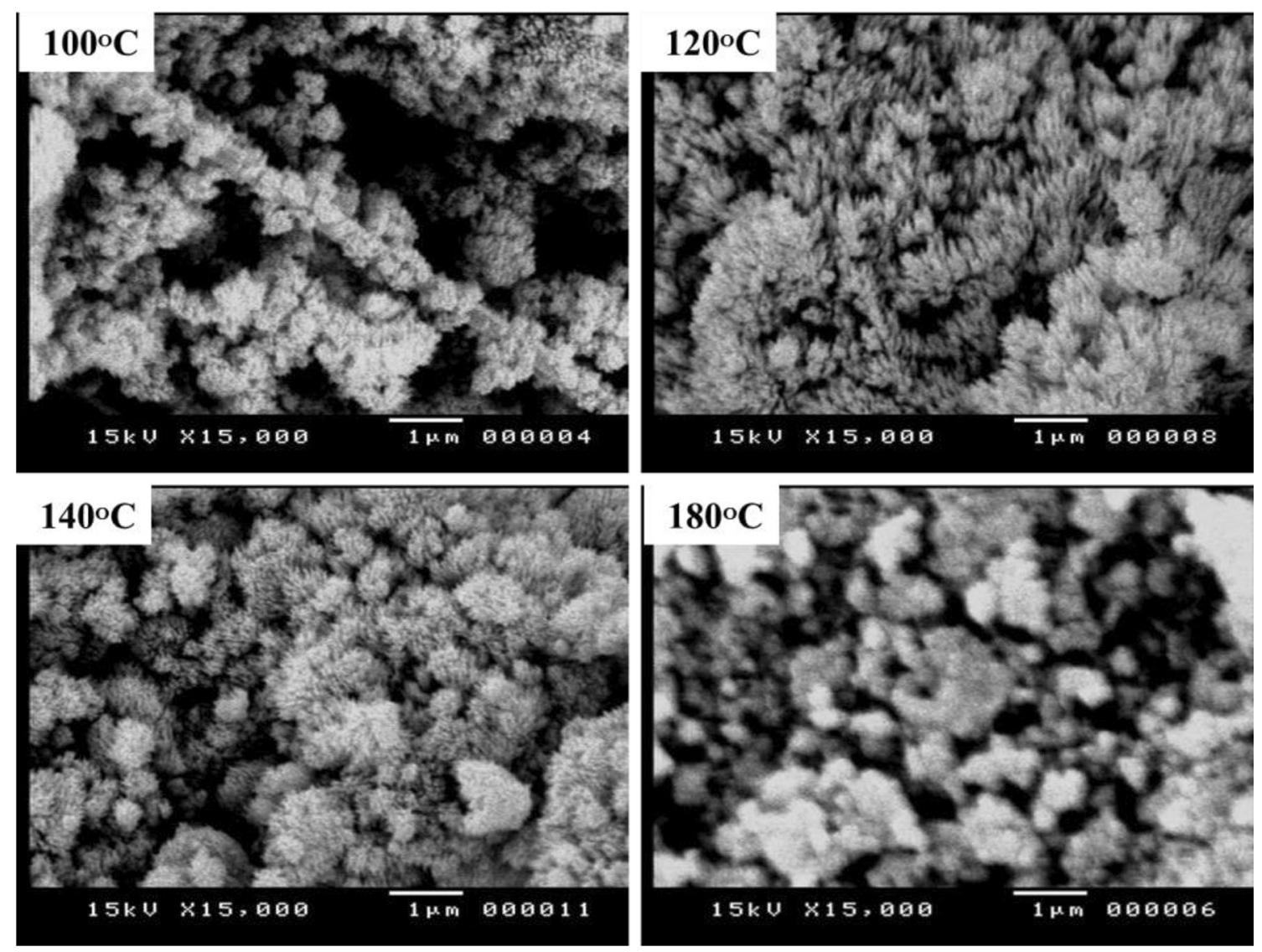

Fig. 2 SEM images of $\mathrm{SnO}_{2}$ observed after annealing of $\mathrm{SnO}_{2}$ prepared at $100-180{ }^{\circ} \mathrm{C}$ 

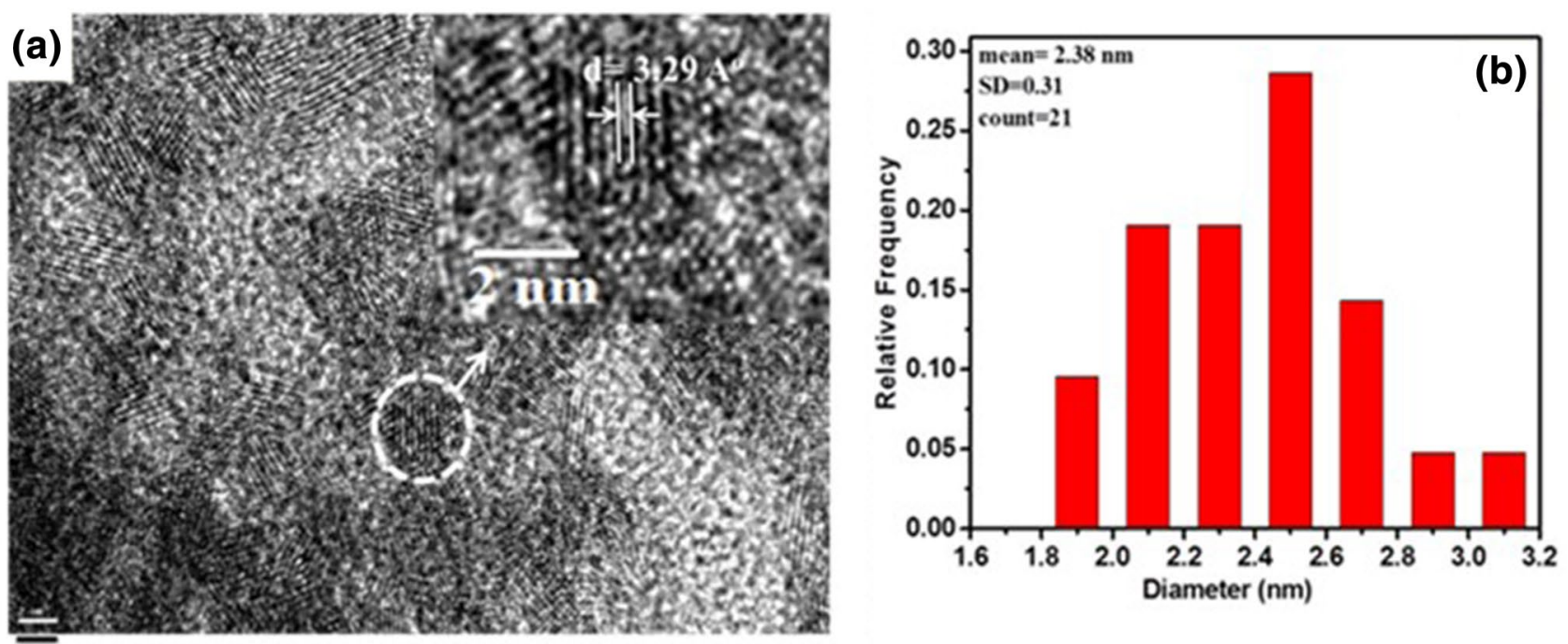

\section{$2 \mathbf{n m}$}
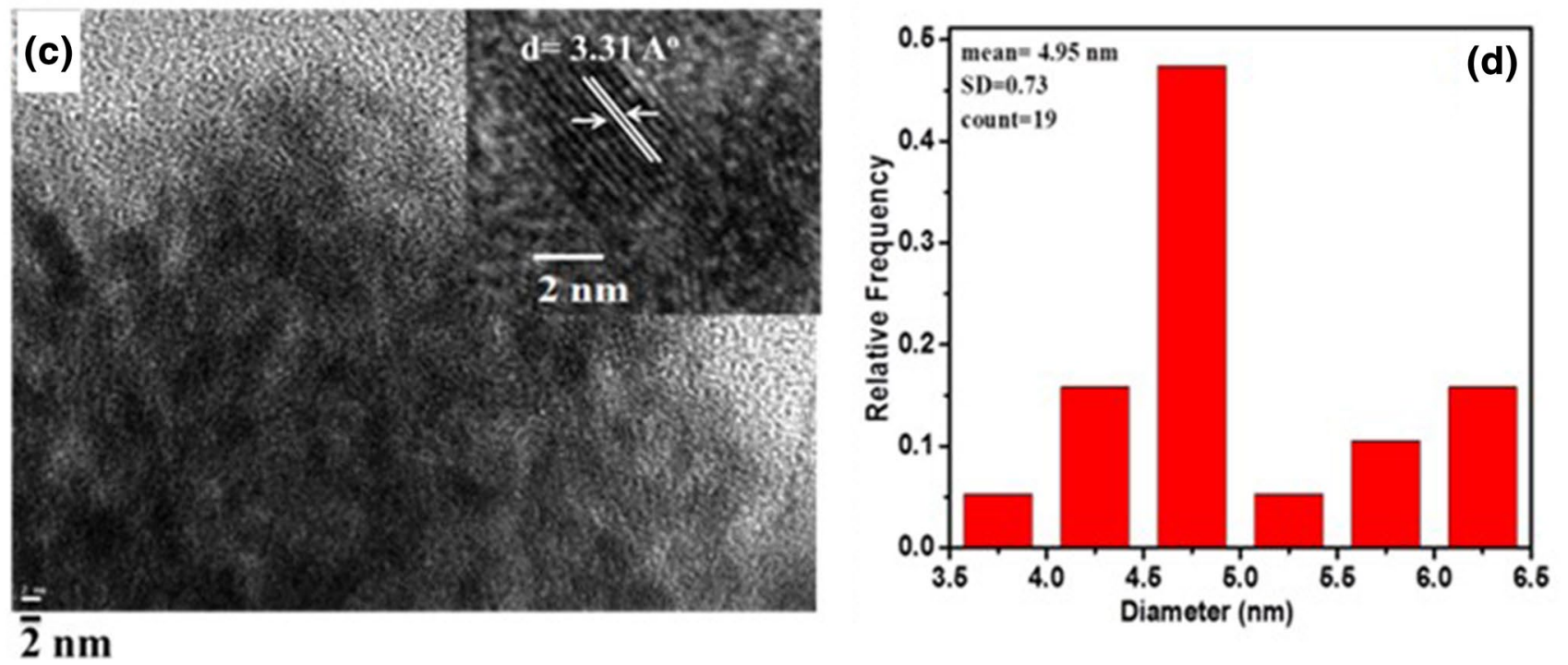

Fig. 3 Typical HRTEM images of as-prepared $\mathrm{SnO}_{2}$ QCs; a 120 , c $180^{\circ} \mathrm{C}$, b, and $\mathbf{d}$ the corresponding crystallite size distribution histograms

the as-prepared samples. This indicates a small increase in both the crystallite size $(D)$ with annealing.

\subsection{Sensing toward $\mathrm{CH}_{4}$ gas}

The as-prepared $\mathrm{SnO}_{2}$ is insensitive and its signal is not stable even at high temperatures, as shown in Fig. 7. Furthermore, the existence of gas causes an increase in the sensor resistance which is irregular behavior of reducing gas with n-type materials. This may be attributed to the change observed in the DTA curve in the range of $200-400{ }^{\circ} \mathrm{C}$. The chemically bonded water molecules may prevent adsorbed oxygen to react with the surface or causes a barrier between oxygen and conduction electrons. The elimination of water molecules causes that the sensor is unstable, as well. Thus, we have considered the heat treatment for $\mathrm{SnO}_{2}$ at
$400{ }^{\circ} \mathrm{C} / 2 \mathrm{~h}$. Consequently, the sensor response has been dramatically improved, as shown in Fig. 8. The decrease in resistance due to the exposure to $\mathrm{CH}_{4}$ gas confirms the n-type behavior of $\mathrm{SnO}_{2}$. $\mathrm{SnO}_{2}$ conductance is reduced in the air due to the chemisorption of oxygen, however, the chemisorbed oxygen ions react with $\mathrm{CH}_{4}$ and increasing the electrical conductance due to the injection of the captured electrons into the conduction band of the oxide.

The dependence of the response on the crystallite size as a function of operating temperature is shown in Fig. 9. The sensor prepared with very fine crystals is the most sensitive toward $\mathrm{CH}_{4}$. It is clearly seen that the sensor response improved largely with increasing the reciprocal size $(1 / D)$ larger than $0.22 / \mathrm{nm}$ (less than $4.54 \mathrm{~nm}$ ). It is expected that this size is fully depleted or volumedepleted in the air. These sensors show shorter response 

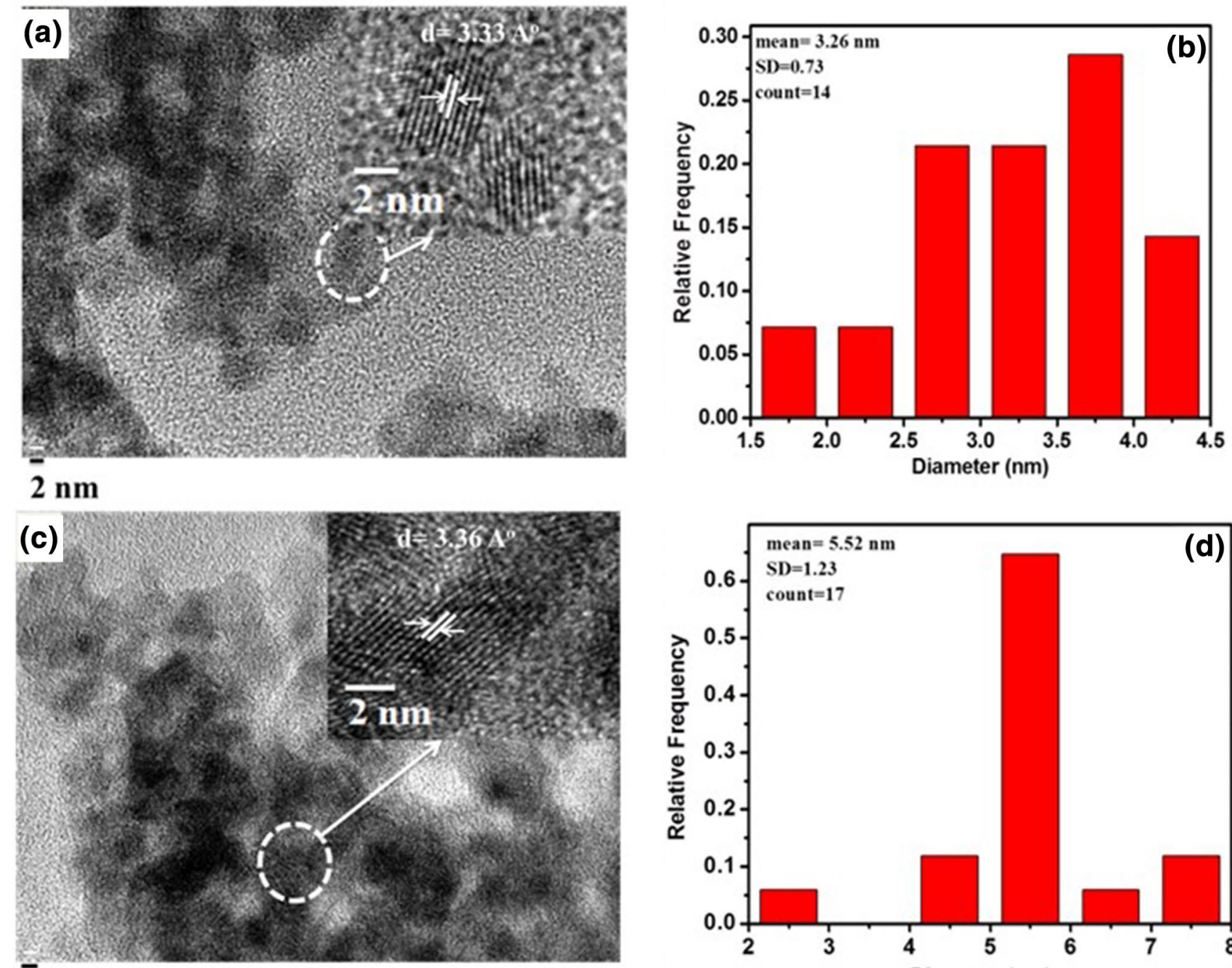

\section{$\overline{2} \mathbf{n m}$}

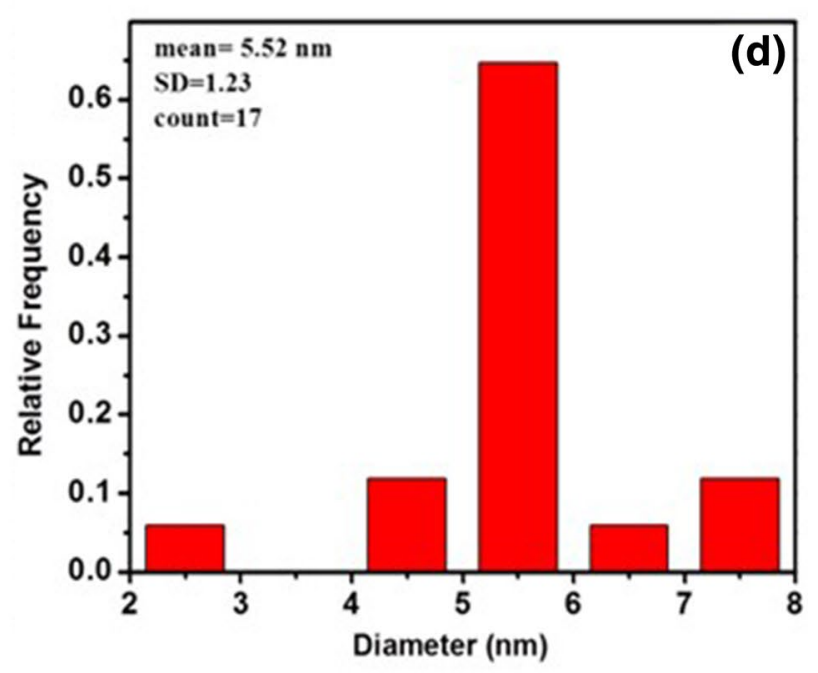

Fig. 4 Typical HRTEM images of $\mathrm{SnO}_{2}$ QCs after annealing at $400{ }^{\circ} \mathrm{C} / 2 \mathrm{~h}$ prepared at temperature, a 120 , c $180{ }^{\circ} \mathrm{C}$, b, and $\mathbf{d}$ the corresponding crystallite size distribution histograms

and recovery times compared with those prepared with larger crystals. The short response and recovery times are attributed to the nanograss-like structure formed by a combination of the fine crystals. It is thought that the gas diffusion and adsorption/desorption process throughout this structure are faster. The sensor response toward $\mathrm{CH}_{4}$ of the present $\mathrm{SnO}_{2}$ QCs is much better than the reported in some literature, as listed in Table 1 . The results are well interpreted if a theoretical approach based on a real condition is developed. Thus, we have proposed a theoretical calculation based on the reaction of $\mathrm{CH}_{4}$ with the oxygen species.

\subsection{Theoretical response of $\mathrm{SnO}_{2}$ toward methane}

Methane (denoted B) reacts with oxygen ions on the surface of crystal semiconductor followed the two reactions.
$O_{2}+2 e=2 O^{-}>200^{\circ} \mathrm{C} \quad$ (in air),

and then

$B+2 O^{-} \rightarrow$ product $+2 e \quad$ (in gas)

The reaction (1) indicates the capture of electrons by oxygen molecules in the air, forming a depletion layer, as shown in Fig. 10. Reaction (2) is the reverse process, which injects the electrons back into the conduction band of the oxide. The chemical equilibrium of adsorbed oxygen on the oxide surface is expressed by:

$\left(K_{O_{2}} P_{O_{2}}\right)[e]_{s}^{2}=\left[O^{-}\right]^{2}$

where $P_{\mathrm{O}_{2}}$ is the partial pressure of oxygen, $K_{\mathrm{O}_{2}}$ the adsorption constant, $[e]_{s}$ the density of conduction electrons, and 

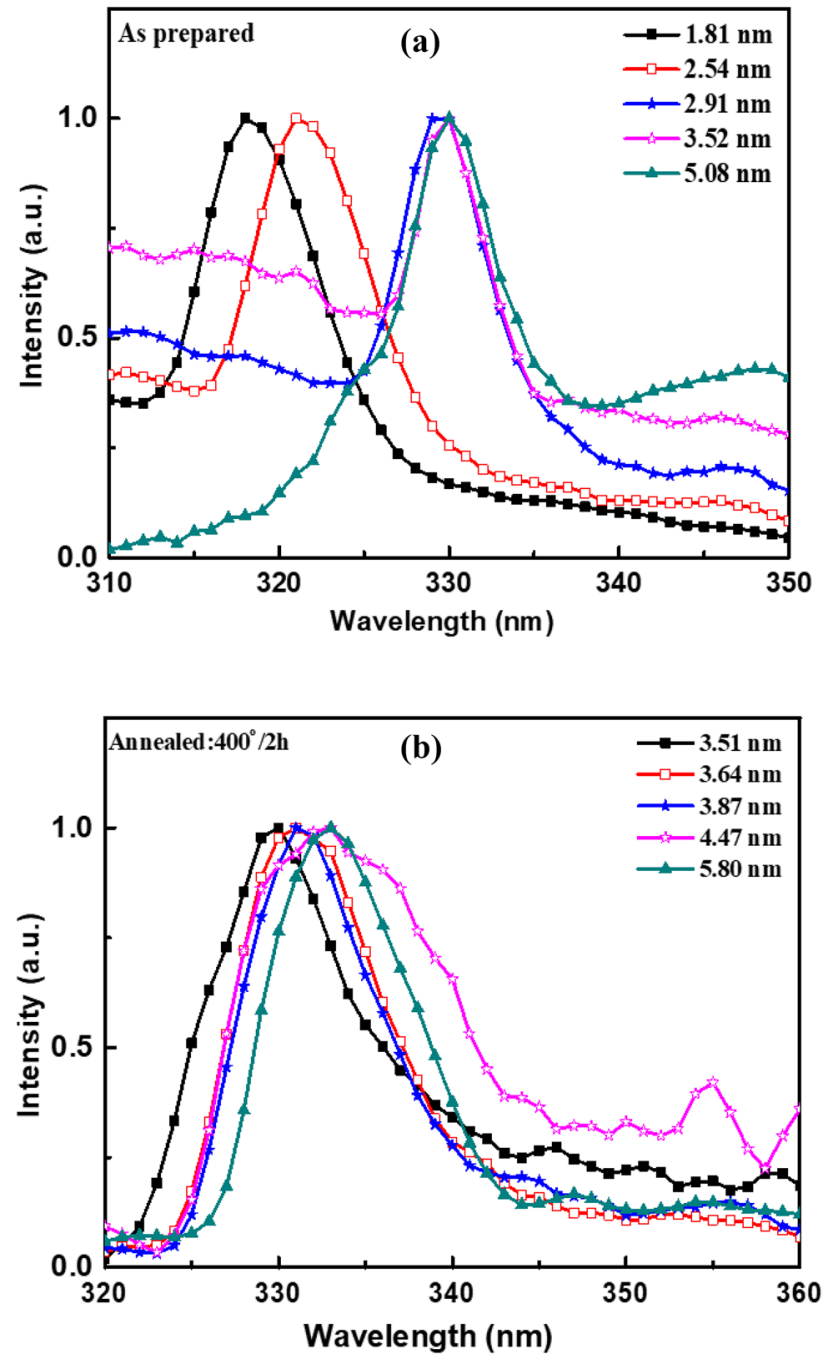

Fig. 5 FL emission spectra at an excitation wavelength of $290 \mathrm{~nm}$; a as-prepared and $\mathbf{b}$ annealed $\mathrm{SnO}_{2}$

$\left[\mathrm{O}^{-}\right]$the surface charge density of oxygen ions. The reduced adsorptive of oxygen is defined by $X=\left(K_{O_{2}} P_{O_{2}}\right)^{1 / 2} / L_{D}$, here $L_{\mathrm{D}}$ is Debye length defined as $L_{D}=\left(q^{2} N_{d} / \varepsilon k T\right)^{-1 / 2}$, where $N_{\mathrm{d}}$ is the donor density, $\varepsilon$ the permittivity material, $q$ the elementary charge, $k$ the Boltzmann constant, and $T$ the absolute temperature.

The adsorption/desorption rate of $\left[\mathrm{O}^{-}\right]$and $\mathrm{CH}_{4}$ is applying as a steady state process. Thus, the above two reactions in equilibrium are expressed as:

$k_{1}\left(P_{O_{2}}\right)[e]_{s}^{2}=k_{-1}\left[O^{-}\right]^{2}+k_{3} P_{\mathrm{CH} 4}\left[O^{-}\right]^{2}$

$\frac{k_{1}}{k_{-1}}\left(P_{O_{2}}\right)[e]_{s}^{2}=\left[O^{-}\right]^{2}\left[1+\frac{k_{3}}{k_{-1}} P_{\mathrm{CH} 4}\right]$
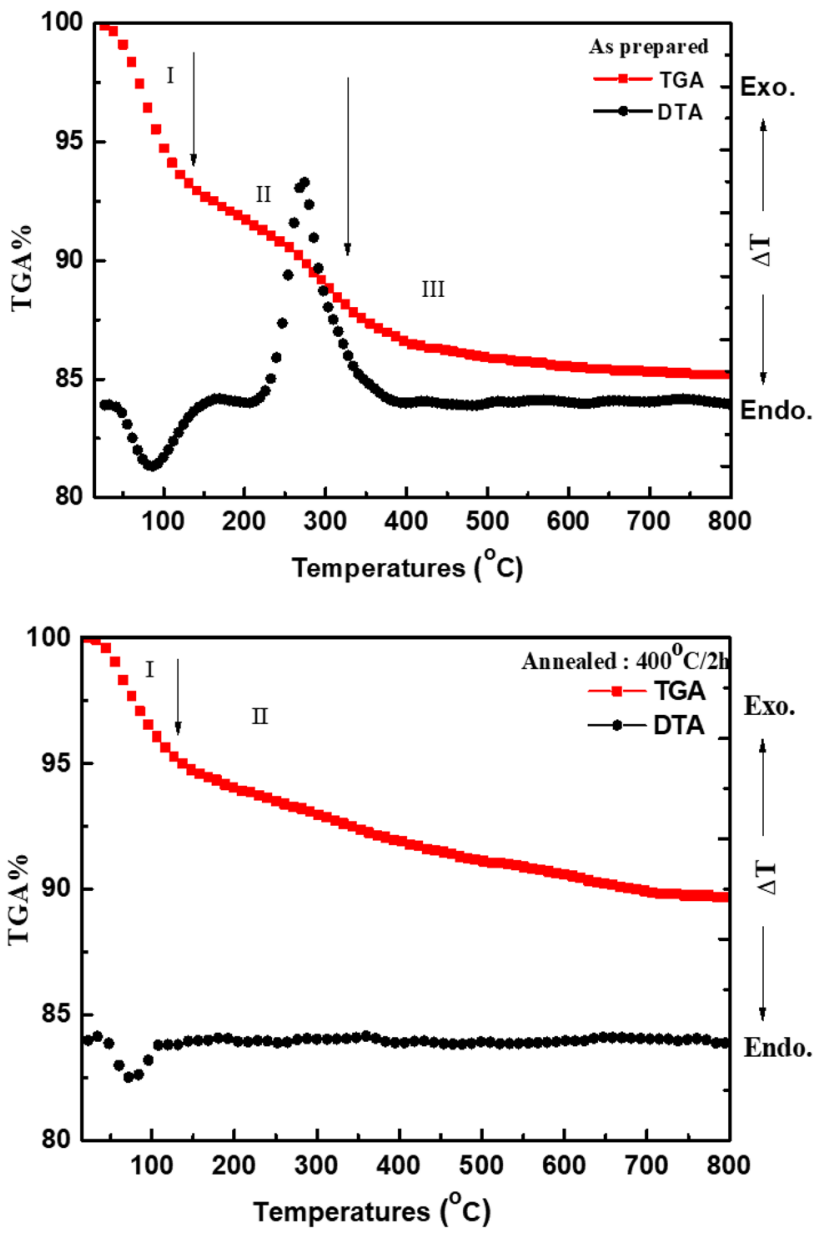

Fig. $6 \mathrm{TGA} / \mathrm{DTA}$ curves at a heating rate $(15 \mathrm{~K} / \mathrm{min})$ for the as-prepared and annealed $\mathrm{SnO}_{2}$

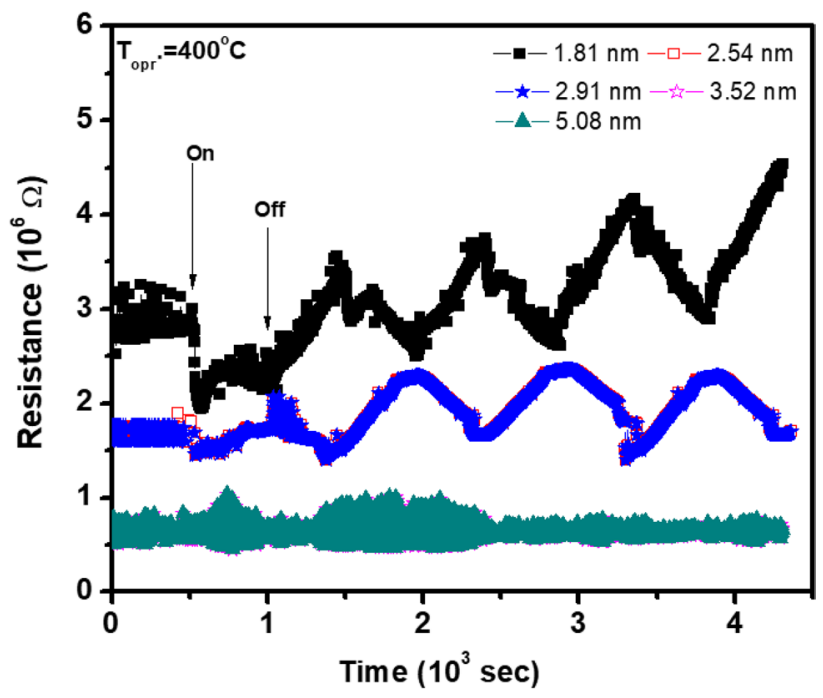

Fig. 7 Sensor signal for as-prepared $\mathrm{SnO}_{2}$ at an operating temperature of $400{ }^{\circ} \mathrm{C}$ 


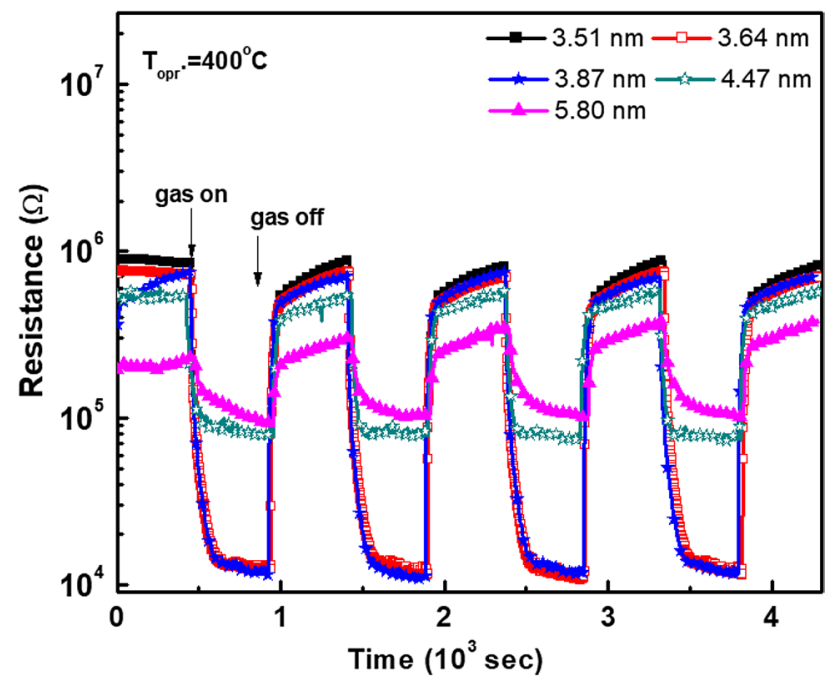

Fig. 8 Sensor signal of annealed $\mathrm{SnO}_{2}$ at the operating temperature of $400{ }^{\circ} \mathrm{C}$

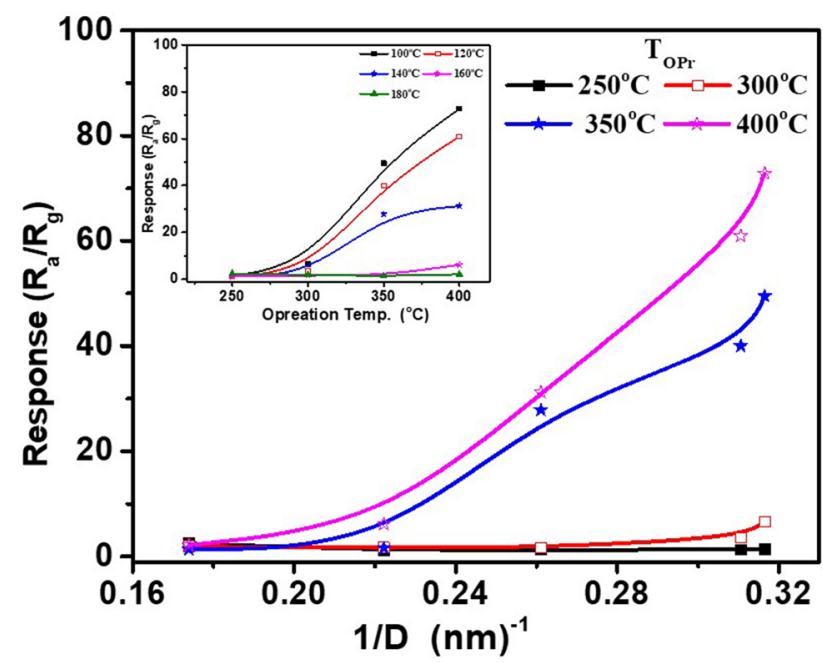

Fig. 9 Sensor response versus the reduced size of $\mathrm{SnO}_{2}$ nanostructures and operating temperature

$$
X^{2}[e]_{s}^{2}=\left[O^{-}\right]^{2}[1+Y]
$$

Here, $Y$ is the partial pressure of the reducing gas $\left(\mathrm{CH}_{4}\right) \cdot k_{1}$ and $k_{-1}$ are the rate constants of forward reaction in Eq. (1) and the reverse reaction in Eq. (2), respectively. In the absence of $\mathrm{B}\left(P_{\mathrm{CH}_{4}}=0\right)$, the Eq. (4) coincides with Eq. (3). The density of conduction electrons and the surface charge density of oxygen ions $O^{-}$are defined as [22, 23]:

$$
\begin{aligned}
& {[e]_{s}=N_{d} \exp \left\{-\frac{q V_{r}}{k T}\right\}, \text { and }} \\
& {[O]^{-}=N_{d} L_{D}\left[\frac{n}{3}-\frac{(n-m)^{3}}{n^{2}}-A_{c}\right]}
\end{aligned}
$$

\begin{tabular}{|c|c|c|c|c|}
\hline Sensing material & $\begin{array}{l}\text { Operat- } \\
\text { ing temp. } \\
\left({ }^{\circ} \mathrm{C}\right)\end{array}$ & $\mathrm{CH}_{4} \%$ & $\begin{array}{l}\text { Response } \\
\mathrm{R}_{\mathrm{g}} / \mathrm{R}_{\mathrm{a}}\end{array}$ & References \\
\hline Porous $3 \mathrm{D} \mathrm{SnO}_{2}$ & 120 & 0.05 & 1.8 & {$[1]$} \\
\hline $\begin{array}{l}\mathrm{SnO}_{2} \mathrm{NR}-\mathrm{NP}-\mathrm{Gr} \\
\text { hybrids }\end{array}$ & 150 & 1.00 & 50 & {$[2]$} \\
\hline $\mathrm{Pt} / \mathrm{SnO}_{2}$ & 400 & 0.50 & 30 & {$[3]$} \\
\hline PdPt-SnO 2 -rGO & 150 & 69.5 & 0.1 & [4] \\
\hline $\mathrm{Co}_{3} \mathrm{O}_{4} \mathrm{NPs}$ & 200 & 1.00 & 1.28 & [10] \\
\hline $\mathrm{Pt}-\mathrm{SnO}_{2}$ & 350 & 0.10 & 4.50 & {$[11]$} \\
\hline $\mathrm{Ag}-\mathrm{SnO}_{2}$ & 430 & 0.20 & 1.75 & {$[12]$} \\
\hline $\mathrm{SnO}_{2}$ & 250 & 0.1 & 20.0 & {$[13]$} \\
\hline $\mathrm{SnO}_{2} @ \mathrm{rGO}, \mathrm{PANI}$ & 27 & 1.0 & 1.9 & [14] \\
\hline $\mathrm{Sn}_{0.9-\mathrm{x}} \mathrm{In}_{0.1} \mathrm{Cu}_{\mathrm{x}} \mathrm{O}_{2}$ & 400 & 0.25 & 9.00 & [15] \\
\hline $\mathrm{Pd}-\mathrm{SnO}_{2}$ & 400 & 0.66 & 20.0 & [16] \\
\hline \multirow[t]{2}{*}{$\mathrm{SnO}_{2} \mathrm{Qs}$} & 350 & 1 & 49.44 & Present \\
\hline & 400 & & 72.76 & \\
\hline
\end{tabular}

Table 1 Comparison sensing characteristic of this work with other recent studies

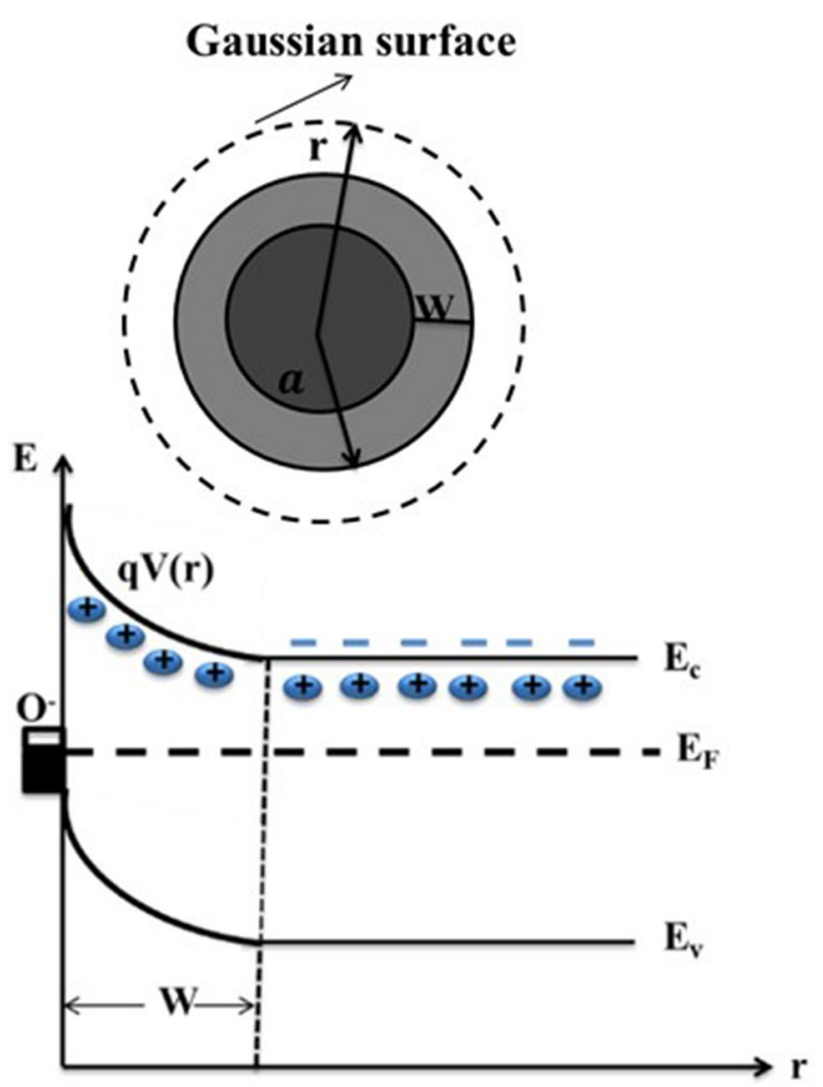

Fig. 10 Formation of the depletion layer for n-type oxide under exposure to an oxygen atmosphere

where $n, m$, and $A_{\mathrm{c}}$ are the reduced radius of the $\mathrm{SnO}_{2}$ sphere, reduced depletion layer and correction term considering the electrons left behind in the depleted region, respectively. 
Based on Fig. 10, the potential energy for the sphere crystals in the air is given by the following equation: and,

$\frac{q V_{r}}{k T}=\left(\frac{1}{3}\right)\left[\frac{n^{2}}{2}-\frac{3}{2}(n-m)^{2}+\frac{(n-m)^{3}}{n}\right]$ (regional depletion)

and

$\frac{q V_{v}}{k T}=\frac{q V_{b}}{k T}+p=\left[\frac{n^{2}}{6}+p\right] \quad$ (volume depletion)

Under the presence of $\mathrm{CH}_{4}$, the correlation between the depletion layer and gas concentration is determined based on the dependence of the depletion layer formed in the air:

$$
\begin{aligned}
X= & \left\{\frac{n}{3}\left(1-\left(\frac{n-m_{a}}{n}\right)^{3}\right)-A_{c}\right\} \\
& \times \exp \left\{\frac{m_{a}^{2}}{6}\left(1+\frac{2\left(n-m_{a}\right)}{n}\right)\right\} \quad \text { (regional depletion) }
\end{aligned}
$$

then $X_{v}=\left\{\frac{n}{3}-A_{c} \exp \left(-p_{a}\right)\right\} \exp \left\{\frac{n^{2}}{6}+p_{a}\right\} \quad$ (volume depletion)

where $m_{a}$ and $P_{a}$ stand for the depletion layer and the extending in Fermi level in the presence of air. The volume depletion is the dominant mechanism ( $m=n$ and Fermi level shift by $p \mathrm{k}_{\mathrm{B}} \mathrm{T}$ ) in case of sphere radius is less than the double of Debye length.

To the precise calculation of the sphere response, the conductance is calculated based on the change in the depth of the depletion layer $(m)$. Thus, the sphere is assumed to be partially depleted as shown in Fig. 10, and then the conductance, $G$ is expressed as.

$G=\int_{0}^{n-m} \frac{A \sigma_{B}}{2 \pi R} d R$ (bulkregion) $+\int_{n-m}^{n} \frac{A \sigma(R)}{2 R} d R$ (depletedregion)

where $\sigma_{B}=q \mu_{B} N_{d}$ and $\sigma(R)=q \mu_{B}[e]_{s}$ are the conductivities of bulk, and depleted region, respectively. $R=r / L_{\mathrm{D}}$, is the reduced sphere radius. Thus, the conductance is expressed as:

$G=c \int_{0}^{n-m} R d R+c \int_{n-m}^{n} R \exp \left\{-\frac{q V_{r}}{k T}\right\} d R \quad$ (Regional depletion)

$G=c \int_{0}^{n} R \exp \left\{-\frac{q V_{v}}{k T}\right\} d R \quad$ (Volume depletion)

Thus, the sensor responses, $S R$, toward $\mathrm{CH}_{4}$ is calculated using Eqs. (6)-(13) as:

$S R=\frac{G_{g}}{G_{a}}$

where $G_{a}$ and $G_{g}$ are the conductance of the sensor in the air and in $\mathrm{CH}_{4}$, respectively. Thus, we consider Eq. (14)

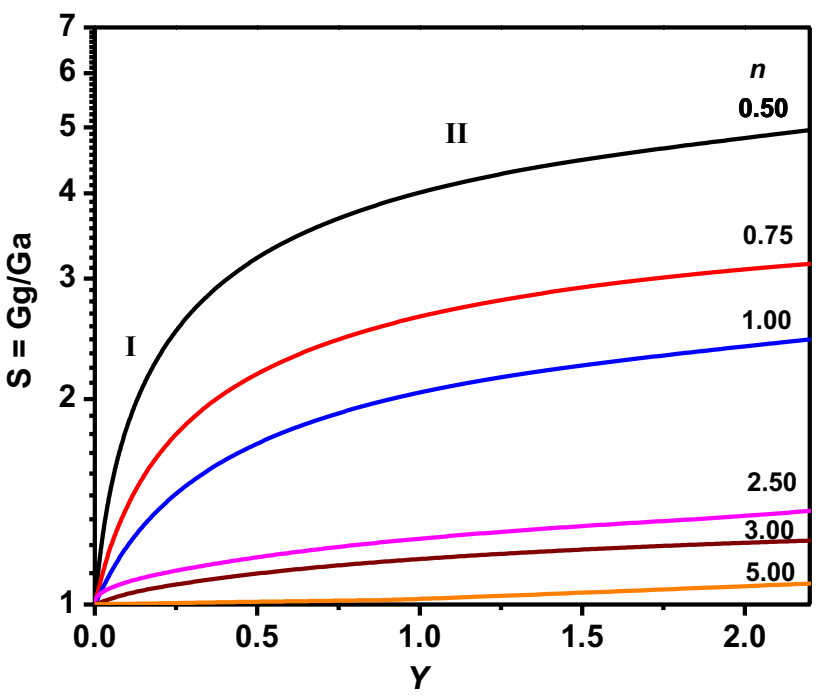

Fig. 11 Calculated response versus $\mathrm{CH}_{4}$ gas concentration for the variously reduced radius of the $\mathrm{SnO}_{2}$ sphere. Note: In the region, I, the increase in sensor response is proportional to the gas concentration, but it is insignificant in region II. This explains the importance of fully depleted particles

for the calculation of SR if the crystal is large and partially depleted. While Eq. (15) is considered for the fine crystal which is fully depleted in air. Upon the exposure $\mathrm{CH}_{4}$, the crystal may be transferred from a volume to regional depletion, thus, both Eqs. (14) and (15) are used. Based on these theoretical bases, the calculated sensitivity as a function of $\mathrm{CH}_{4}$ concentration is shown in Fig. 11. The crystals which were in a volume depletion in the air are highly sensitive than those in a regional depletion. The sensor response tends to a steady value with more increase in the gas concentration. The steady values are dependent on the radius of the sphere, where it raises up with decreasing the radius. It may be logic to say that the depletion layer formed due to oxygen ions in the air is bit-by-bit reduced with increasing $\mathrm{CH}_{4}$ concentration. Therefore, the higher gas concentration had a negligible effect on the electrical conductivity, resulting in a less change in the sensor response with a further increase in the gas concentration. Figure 12 shows the calculated response as a function of the reduced radius at gas concentrations of $0.5,1.0$, and 2.0. The response of the large sphere $(1 / n<0.375)$ which is partially depleted in the air is very low, because of the depletion layer thickness compared to bulk crystals is small. Moreover, the electron transfer can take place through the bulk area far from the surface. The response was much improved with the fine sphere $(1 / n>0.375)$ which was in a volume depletion in the air.

A similar result is drawn for the experimental part shown in Fig. 9. This result suggests that the QCs with $3.5 \mathrm{~nm}$ and $3.6 \mathrm{~nm}$ in the presence of air are fully depleted, while the 


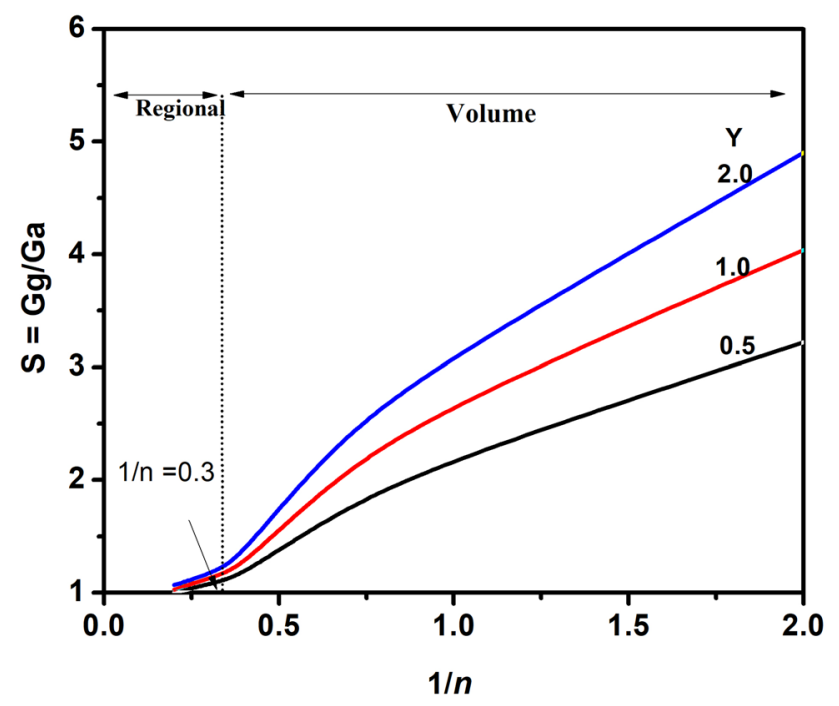

Fig. 12 Calculated response versus the reciprocal radius of the sphere. Note: the sensor response is very low in regional depletion $(1 / n<0.3$ or $n>3.3)$, but it is high in volume depletion or $n<3.3$

larger QCs are partially depleted in the same condition. It is a reasonable result where the Debye length of $\mathrm{SnO}_{2}$ in the air is about $\sim 3.0 \mathrm{~nm}$ at $250{ }^{\circ} \mathrm{C}$, suggesting that the crystals with $6.0 \mathrm{~nm}$ might be regional-depleted, and $3.0 \mathrm{~nm}$ is volume depleted in the air. The current proposed approach is appropriate for the interpretation of the reaction mechanism of the methane gas with the n-type oxide.

\section{Conclusions}

Thermal stable $\mathrm{SnO}_{2}$ quantum crystals with a size smaller than the Debye length were synthesized. The thermal annealing has an insignificant effect on the crystallite size but has a significant effect on the gas sensing properties. The QCs grew in nanograss-like structure with a directional growth of (110). This structure with its small crystals showed a high response and short response and recovery times toward methane. The crystal size of the prepared $\mathrm{SnO}_{2}$ is comparable or smaller than the Debye length of $\mathrm{SnO}_{2}$, which allowed for the QCs to be a fully depleted or volume-depleted in the air. Consequently, the gas has a large chance to react with much oxygen species and has a significant impact on oxide conductivity. A theoretical approach is proposed for explaining the gas sensing mechanism of $\mathrm{CH}_{4}$ and $\mathrm{SnO}_{2}$. The proposed theoretical calculation confirmed this expectation and suggested that the fine crystals were volume-depleted in the air, whareas, the larger crystals were regional-depleted. Thus, the fine crystals expressed a high response toward $\mathrm{CH}_{4}$ gas, while the larger crystals expressed a low response.
Acknowledgements This work funded by DeanShip of scientific research (DSR), King Faisal University, Al-Hassa, KSA under grant No. 186114. The authors thank DSR technical and financial support.

Data availability The data used to support the findings of this study are included in the article.

Open Access This article is distributed under the terms of the Creative Commons Attribution 4.0 International License (http://creativeco mmons.org/licenses/by/4.0/), which permits unrestricted use, distribution, and reproduction in any medium, provided you give appropriate credit to the original author(s) and the source, provide a link to the Creative Commons license, and indicate if changes were made.

\section{References}

1. D. Xue, S. Zhang, Z. Zhang, Hydrothermally prepared porous $3 \mathrm{D} \mathrm{SnO}_{2}$ microstructures for methane sensing at lower operating temperature. Mater. Lett. 237, 336-339 (2019)

2. M. Kootia, S. Keshtkara, M. Askariehb, A. Rashidi, Progress toward a novel methane gas sensor based on $\mathrm{SnO}_{2}$ nanorods nanoporous graphene hybrid. Sens. Actuators B 281, 96-106 (2019)

3. F.S. Fateminia, Y. Mortazavi, A.A. Khodadadi, Au-promoted $\mathrm{Ce}-\mathrm{Zr}$ catalytic filter for $\mathrm{Pt} / \mathrm{SnO}_{2}$ sensor to selectively detect methane and ethanol in the presence of interfering indoor gases. Mater. Sci. Semicond. Process. 90, 182-189 (2019)

4. S. Navazani, A. Shokuhfar, M. Hassanisadi, A.D. Carlo, N.Y. Nia, A. Agresti, A PdPt decorated $\mathrm{SnO}_{2}-\mathrm{rGO}$ nanohybrid for highperformance resistive sensing of ethane. J. Taiwan Inst. Chem. Eng. 95, 438-451 (2019)

5. S. Nasresfahani, M.H. Sheikhi, M. Tohidi, A. Zarifkar, Methane gas sensing properties of Pd-doped $\mathrm{SnO}_{2}$ /reduced graphene oxide synthesized by a facile hydrothermal route. Mater. Res. Bull. 89, 161-169 (2017)

6. X. Liu, S. Cheng, H. Liu, S. Hu, D. Zhang, H. Ning, A survey on gas sensing technology. Sensors 12, 9635-9665 (2012)

7. A. Das, V. Bonu, A.K. Prasad, D. Panda, S. Dhara, A.K. Tyagi, The role of $\mathrm{SnO}_{2}$ quantum dots in improved $\mathrm{CH}_{4}$ sensing at low temperature. J. Mater. Chem. C 2, 164-171 (2014)

8. G. Fedorenko, L. Oleksenko, N. Maksymovych, G. Skolyar, O. Ripko, Semiconductor Gas Sensors Based on $\mathrm{Pd} / \mathrm{SnO}_{2}$ Nanomaterials for Methane Detection in Air. Nanoscale Res. Lett. 12, 329-338 (2017)

9. P. Dhivya, A.K. Prasad, M. Sridharan, Effect of sputtering power on the methane sensing properties of nanostructured cadmium oxide films. J. Alloy. Comp. 620, 109-115 (2015)

10. N.M. Shaalan, M. Rashad, A. Moharram, M. Abdel-Rahim, Promising methane gas sensor synthesized by microwave-assisted $\mathrm{Co}_{3} \mathrm{O}_{4}$ nanoparticles. Mater. Sci. Semi. Process. 46, 1-5 (2016)

11. W. Lu, D. Ding, Q. Xue, Y. Du, Y. Xiong, J. Zhang, X. Pan, W. Xing, Great enhancement of $\mathrm{CH}_{4}$ sensitivity of $\mathrm{SnO}_{2}$ based nanofibers by heterogeneous sensitization and catalytic effect. Sens. Actuators B 254, 393-401 (2018)

12. Z.K. Horastani, S.M. Sayedi, M.H. Sheikhi, E. Rahimi, Effect of silver additive on electrical conductivity and methane sensitivity of $\mathrm{SnO}_{2}$. Mater. Sci. Semi. Process. 35, 38-44 (2015)

13. S. Navazani, A. Shokuhfar, M. Hassanisadi, M. Askarieh, A.D. Carlo, A. Agresti, Facile synthesis of a $\mathrm{SnO}_{2} @ \mathrm{rGO}$ nanohybrid and optimization of its methane-sensing parameters. Talanta 181, 422-430 (2018)

14. S. Navazani, A. Shokuhfar, M. Hassanisadi, A.D. Carlo, N. Shahcheraghi, Fabrication and characterization of a sensitive, room 
temperature methane sensor based on $\mathrm{SnO}_{2} @$ reduced graphene oxide-polyaniline ternary nanohybrid. Mater. Sci. Semicond. Process. 88, 139-147 (2018)

15. S. Somacescu, P. Osiceanu, J.M. Calderon-Moreno, A. Sackmann, C.E. Simion, A. Stănoiu, Mesoporous $\mathrm{Sn}_{0.9-\mathrm{x}} \mathrm{In}_{0.1} \mathrm{Cu}_{\mathrm{x}}(\mathrm{I}) \mathrm{O}_{2-\delta}$ gas sensors with selectivity to $\mathrm{H}_{2} \mathrm{~S}$ working under humid air conditions. Micro. Meso. Mater. 197, 63-71 (2014)

16. T. Wagner, M. Bauer, T. Sauerwald, C.D. Kohl, M. Tiemann, $\mathrm{X}$-ray absorption near-edge spectroscopy investigation of the oxidation state of $\mathrm{Pd}$ species in nanoporous $\mathrm{SnO}_{2}$ gas sensors for methane detection. Thin Solid Films 520, 909-912 (2011)

17. S. Basu, P.K. Basu, Nanocrystalline metal oxides for methane sensors: role of noble metals, J. Sens. 2009, 861968 (2009)

18. W. Chen, Q. Zhou, L. Xu, F. Wan, S. Peng, W. Zeng, Improved methane sensing properties of co-doped $\mathrm{SnO} 2$ electrospun nanofibers. J. Nanomater. 2013, 4 (2013)

19. C. Xu et al., Relationship between gas sensitivity and microstructure of porous $\mathrm{SnO}_{2}$. J. Electrochem. Soc. Jpn. 58, 1143-1148 (1990)
20. H. Ogawa, M. Nishikawa, A. Abe, Hall measurement studies and an electrical conductive model of tin oxide ultrafine particle films. J. Appl. Phys. 53, 4448-4454 (1982)

21. W. Wei, H. Xu, Q. You, Q. Cheng, C. Liu, L. Zou, X. Liu, Preparation of quantum dot luminescent materials through the ink approach. Mater. Des. 91, 165-170 (2016)

22. N. Yamazoe, K. Suematsu, K. Shimanoe, Extension of receptor function theory to include two types of adsorbed oxygen for oxide semiconductor gas sensors. Sens. Actuators B 163, 128-135 (2012)

23. N. Yamazoe, K. Shimanoe, Theoretical approach to the rate of response of semiconductor gas sensor. Sens. Actuators B 150, $132-140(2010)$

Publisher's Note Springer Nature remains neutral with regard to jurisdictional claims in published maps and institutional affiliations. 